\title{
La tragedia del AF 447 y las revistas brasileñas ${ }^{1}$
}

\section{The Tragedy of the Airline AF 447 and the Brazilian Magazines}

\author{
Maria das Graças Targino \\ Universidad Estadual del Piauí \\ gracatargino@hotmail.com
}

\section{Alisson Dias Gomes}

Facultad San Agustín

alissondg@bol.com.br

\begin{abstract}
Resumen
El accidente de Air France, (2009), ocupó un gran espacio en los medias de comunicación tanto por el elevado número de víctimas de 33 países como por las discusiones acerca de la seguridad aérea. Tres de las revistas brasileñas informativas de mayor relevancia en el país, Veja, Época e IstoÉ, reprodujeron lo ocurrido en sus portadas de la edición después del accidente: el 8 de junio de 2009 (Época) y el 10 de junio, en Veja e IstoÉ. Como estas revistas vienen experimentando un crecimiento expresivo en la prensa escrita y electrónica, es objetivo de este paper el analizar los discursos de portada de las mencionadas ediciones, según la perspectiva del análisis de discurso de Norman Fairclough.
\end{abstract}

Palabras clave: Análisis del discurso, Norman Fairclough, Revistas brasileñas informativas.

\begin{abstract}
The crash of the airline Air France, 2009, held in the media, both by the high number of victims from 33 countries and the discussions about the safety of aviation. The three Brazilian news magazines, Veja, Época and IstoÉ, reproduced in their covers June $8^{\text {th }} 2009$ (Época) and June $10^{\text {th }}$ (Veja and IstoÉ) the happening. As the magazine has become a media of significant growth in electronic and printed media, the purpose of this paper is to analyze the discussion of these covers, from the perspective of the method of analysis of the speech mentioned by Norman Fairclough.
\end{abstract}

Keywords: Analysis of the speech, Norman Fairclough, Brazilian news magazine.

\footnotetext{
${ }^{1}$ Los autores agradecen al Profesor Doctor Francisco Laerte Juvêncio Magalhães, por la lectura de los originales y por sus valiosas contribuciones, en la condición de experto en análisis del discurso
} 


\section{Introducción}

Mayo de 2009. Día 31. Una aeronave hasta entonces considerada segura por su avanzada tecnología de a bordo y por el renombre de la compañía aérea a la que pertenece, la francesa Air France, lleva a la profundidad del océano Atlántico, después del decolaje a las 19h30 horas del Aeropuerto Internacional Tom Jobim, el Galeão, Río de Janeiro, en dirección a París, los sueños de 228 individuos de 33 diferentes nacionalidades, de credos distintos, de los dos sexos y de las variadas franjas de edad, incluyendo niños, jóvenes, adultos y ancianos.

Un accidente aéreo que adquirió proporciones gigantescas en Francia y en Brasil, países con la cantidad más grande de víctimas, respectivamente: 61 y 58 , además de atingir naciones cercanas, como Argentina (una sola víctima) y otras más lejanas: Alemania (26), China (nueve), Italia (nueve), Suiza (seis), Reino Unido (cinco), Líbano (cuatro), Hungría (cuatro), Irlanda (tres), Noruega (tres), Eslovaquia (tres), Polonia (dos), Estados Unidos de América (EUA, dos), España (dos), Marruecos (dos), además de sendos representantes de origen surafricano, austriaco, belga, canadiense, croata, coreano, danés, holandés, estoniano, filipino, gambiano, islandés, rumano, ruso, sueco y turco. A las 22h33, la tripulación contactó por última vez con los controladores aéreos brasileños. El avión sobrevolaba el Atlántico, a $565 \mathrm{Km}$. de la capital potiguar, Natal, cerca de las islas brasileñas de Fernando de Noronha. Y, desde entonces, especialistas franceses y brasileños intentan desvendar las causas del accidente como forma de asegurar el futuro de la aviación en términos de seguridad.

Ante el hecho ocurrido, los medios de comunicación de todo el mundo, en todo tipo de soportes destinaron una gran cantidad de espacio para cubrir la tragedia del AF 447. En el caso de Brasil, llama la atención el comportamiento de las tres revistas semanales informativas con mayor tirada (ver Tabla 1), Veja, Época e IstoÉ.

Tabla 1 - Revistas brasileñas con mayor circulación, 2008

SEMANALES

Título Media por edición Variación (\%)

$\begin{array}{lll}\text { Veja } & 1.089 .902 & -0,8 \%\end{array}$

Época $\quad 420.477 \quad 0,6 \%$

IstoÉ $\quad 355.136 \quad 2,6 \%$

Fuente: Instituto Verificador de Circulação.

Reproducen el acontecimiento en sus portadas de la edición después del accidente: el 8 de junio de 2009 (Época) y el 10 de junio, en el caso de Veja e IstoÉ. Eso refuerza la idea de que la agenda social recibe interferencias directas de la agenda mediática, sea en un ámbito nacional o internacional, una vez que se ha dado la repetición del tema de realce tan pronto después, como ya ocurriera cuando también las tres llevaron a su portada el 
fallecimiento del cantante norteamericano Michael Jackson en sus ediciones del 27 de junio (Época) y 1 de julio (Veja e IstoÉ). Incluso hay un ejemplo estudiado por Targino y Gomes (2008): la edición del 8 de febrero de 2007 de cuatro periódicos gratuitos de España ( $A D N, Q u e ́$, Metro, 20 Minutos) cuando exponen, en la primera página, la misma fotografía de la hermana menor de la Princesa de Asturias, Leticia Ortiz Rocasolano, como consecuencia de su trágica muerte.

Sin embargo, en el caso de las tres revistas informativas brasileñas, debido a la repercusión nacional de la noticia del accidente del vuelo Air France 447, es objetivo central del paper el analizar los discursos de las portadas de las ediciones citadas, según la perspectiva del análisis del discurso $(\mathrm{AD})$ del británico Norman Fairclough. El AD es un campo de las ciencias del lenguaje, noción más amplia que la de comunicación y destinada al análisis de las construcciones ideológicas presentes en cualquier texto, con énfasis en los mediáticos. En otras palabras, el $\mathrm{AD}$ tiene como objetivo observar los aspectos formales de los modos de producción, circulación y consumo de sentidos y a partir de ahí, otros ítems consecuentes: disputas, estrategias, silencios, interdicciones, etc.

Además, es sencillo justificar la selección de la revista informativa. Las razones son distintas y variadas. Primero, su crecimiento en la prensa brasileña. Aunque Sant'Anna (2009b) afirme que Brasil está muy lejos de los países primer mundistas en relación al tiraje de las revistas existente versus contingente poblacional, una vez que, en una población en torno a los 190 millones de habitantes, el total de ejemplares vendidos por persona no llega a tres por año, en contraposición a los EUA y a Francia, cuyo total asciende, respectivamente, a 10 y 18 ejemplares por habitante. A pesar de todo, la revista informativa viene ocupando más espacio en la sociedad brasileña y conquistando nuevos lectores y credibilidad. Según los dados del Projeto Inter-Meios y del Instituto Verificador de Circulação (IVC), el último, una empresa que, desde los años 60 del siglo XX controla la difusión de las publicaciones nacionales a ellos asociadas, la tirada media de las revistas tiende a crecer (Tabla 2), lo que significa que la circulación de revistas compradas aumentó, de media, un 7,5\% en relación al año 2007 / 2008, como Sant'Anna (2009a) sintetiza.

Tabla 2 - Desarrollo de las revistas, Brasil, años 2007-2008

\begin{tabular}{llll} 
& $\mathbf{2 0 0 7}$ & $\mathbf{2 0 0 8}$ & Crecimiento \\
Circulación media por edición & 13,3 millones & 14,3 millones & $7,5 \%$ \\
Ventas por unidades & 6,3 millones & 6,8 millones & $7,5 \%$ \\
Ventas por firmas & 6,9 millones & 7,4 millones & $7,1 \%$ \\
\hline
\end{tabular}

Fuentes: Instituto Verificador de Circulação y Projeto Inter-Meios.

Una segunda razón para justificar la selección de las revistas informativas son las tentativas por ellas emprendidas para llevar a menos la fuerza del soporte electrónico y 
acompañar los desarrollos tecnológicos. Los sitios correspondientes a los títulos priman cada vez más por una identidad hipermediática al incorporar otros media y, aun, por la creciente interactividad e hipertextualidad, en la búsqueda de suprimir las demandas de los ciudadanos, de forma individualizada, permitiendo a cada uno seleccionar el material que va a leer / ver / oír, cuándo y cómo, al tiempo en que estimula la profundización de cuestiones emergentes en el decorrer de la búsqueda. La interactividad prevé oportunidades de participación del público-lector para expresar opiniones, votar y posicionarse. La hipertextualidad, por su parte, traspasa los textos. Incluye gráficos, sonidos, fotos, narración o secuencias animadas.

Entre otros motivos del ascenso de la revista como medio de comunicación está la función más educativa, con su inserción como fuente de consulta en la enseñanza. El proyecto más antiguo, año 1998, es de la Editora Abril. Se trata de Veja en el Aula. Semanalmente, cuatro reportajes de Veja tienen sus contenidos adaptados a temas relacionados con la enseñanza secundaria con el apoyo de cinco mil profesores que cuentan con asignaturas, además de una página web que ofrece todos los materiales necesarios. Otro proyecto, también de la revista Veja, data de 2008. Cuando por su $40^{\circ}$ cumpleaños la Editora promocionó una serie de debates acerca de temas como política, seguridad, legislación, justicia y economía, mediante la realización de una consulta a más de 500 especialistas. Versiones reducidas del material producido están siendo llevadas a la enseñanza de secundaria para la discusión entre maestros y alumnos universitarios, además de la presencia de periodistas y personalidades de renombre en las diferentes áreas.

Aunque existan diferentes tipos de revistas, tales como los títulos de ocio, que priorizan el divertimiento y la distracción, o el ejemplo de los comics o títulos, como Capricho y Caras, para Sant'Anna (2009a), a favor de la revista como medio de comunicación, constata que, al contrario de los EUA y Europa, donde los títulos destinados a los jóvenes están en declive, en Brasil, dos de los periódicos con mayor incremento de circulación en 2008 están destinados a ese público. Capricho conquistó el primer puesto, con un $40 \%$ de aumento en el número de ejemplares y Mundo Estranho, el tercer puesto, con un 30\%. Además, la revista mensual de la Turma da Mônica Jovem, de la Editora Panini, en 2008, cuyo número inicial empezó con 340 mil ejemplares, en el cuarto fascículo llegó a una tirada de 400 mil ejemplares. También entre los niños las revistas obtienen éxito, gracias a las iniciativas bien variadas, como la creación de productos escolares y acciones complementarias en el proceso enseñanza-aprendizaje, tanto para la transmisión de contenidos como para actividades lúdicas.

Delante de lo expuesto, después de delinear el perfil de los tres títulos y presentar un referencial en la línea de $\mathrm{AD}$ que permita una compresión más acurada de la disposición de las portadas, siguen la discusión, las consideraciones finales y las fuentes referenciadas. 


\section{Perfil de las revistas informativas brasileñas Veja, Época e IstoÉ}

Como Magalhães (2003) detalla, el tratamiento de la revista tiene el inicio con las versiones ilustradas, al final del siglo XIX, que privilegiaban las caricaturas y los dibujos de humor. En 1936, en Inglaterra, surge el título Life, influenciada por el avance de la prensa europea y del cine como industria. Como consecuencia de su éxito, surgen nuevas revistas ilustradas por todo el mundo en la misma línea de producción, como Look y Holliday (EUA); Picture Post (Reino Unido); Heute y Der Spiegel (Alemania) y Paris Match (Francia). En Brasil, es el turno de O Cruzeiro, año 1928, que alcanza su mayor éxito en los años 50. Antes de $O$ Cruzeiro, la revista Vida Doméstica. Paralelamente, los títulos Sombra; Rio Magazine; A Cigarra; Para-Todos; Careta y Fon-fon, además de Manchete.

Las revistas ilustradas son publicaciones leves, con mucha sofisticación fotográfica, que despiertan el apelo comunista. Sin embargo, los fotorreportajes no excluyen otros géneros periodísticos, tales como la crónica, el comentario político, la sección informativa, las columnas de cotilleos, etc. En una fase histórica sin televisión, las revistas ilustradas asociadas a la radio y a los periódicos impresos reconstituyen los hechos de lo cotidiano. No obstante, la llegada de la TV y su éxito entre los medios de comunicación desplazan el interés de los anunciantes, contribuyendo al declive de esas revistas; en Brasil, sobre todo, al final de los años 50. Es entonces cuando surgen las revistas semanales de información en el país, a partir de la década de los 60, gracias a la influencia de los títulos norteamericanos Time y Newsweek, con el intento de priorizar la información periodística. Magalhães sostiene que:

[...] y, por eso mismo, la materialidad textual adquiere mayor importancia en lo que dice respecto a la materia imagética, en la producción de los discursos de actualidad. No se trata de ofertar un reportaje fotográfico para el deleite del consumidor voyeur sino de ofrecer al ejecutivo y/o hombre de negocios el conocimiento minucioso de los hechos, a través de reportajes detallados, que necesita para estar bien informado, identificar nuevas oportunidades y de ellas sacar provecho [...] (2003: 98).

Las revistas Veja (Abril), Época (Globo) e IstoÉ (Três) se posicionan como fuertes concurrentes, incluso, son vendidas a R \$ 8,90 (cerca de 3 euros), cada edición, lo que no es una mera casualidad. Despiertan constantes polémicas entre los profesionales del área de comunicación o entre los ciudadanos de cualquier estatus por sus líneas editoriales aunque, realmente, a menudo, las escondan o ellas se mezclen. Las aproximaciones o los alejamientos se materializan en los discursos de portada y en sus lugares discursivos.

$V e j a$ e IstoÉ tienen un punto en común en lo que se refiere al origen: ambas son productos de Demetrio Giuliano Gianni Carta, periodista, editor, escritor y pintor italo- 
brasileño, nacido en Génova, en 1933, y residente en Brasil desde 1946. Mino Carta coordinó los equipos creadores del Jornal da Tarde (São Paulo) y de las revistas Quatro Rodas, Veja, IstoÉ y Carta Capital, de la que en la actualidad aún es director de redacción.

De entre las tres, Veja es la pionera. Su primer número data de septiembre de 1968, auge del Régimen Militar, lo que representa un inicio pautado por las dificultades, entre las que se encuentran la censura, aprehensión de ediciones y supresión de materias. Hoy es la revista brasileña semanal informativa de mayor circulación, con una tirada superior al millón de ejemplares (Tabla 1), además de ser la cuarta más leída en el ranking mundial, únicamente por detrás de las norteamericanas Time, Newsweek y U.S. News \& World Report, según datos de su página electrónica.

IstoÉ, por su parte, es resultado del alejamiento de Mino Carta de Veja, y de otro director, Domingo Alzugaray. Juntos editan el primer número de la IstoÉ, en mayo de 1976, con periodicidad mensual. Después es vendida a la Gazeta Mercantil y más adelante, en 1988, retorna a la casa de origen, Editora Três. En esa época, el principal título de esa Editora, en el género, era Senhor, destinado al público ejecutivo masculino, priorizando las temáticas políticas y económicas. A IstoÉ se une a Senhor (más o menos en los moldes de la Carta Capital), para pasar a llamarse IstoÉ / Senhor, que sigue hasta marzo de 1992, año en que retoma la designación IstoÉ. Hoy, aún pertenece a Domingo Alzugaray, que figura en el expediente de sus publicaciones, al lado de su mujer Cátia Alzugaray, solamente como editor responsable.

En términos de tirada, factor decisivo para que cualquier cabecera pueda alcanzar el liderazgo de mercado de lectores y anunciantes, según recientes análisis de Sant'Anna (2009b), IstoÉ está por debajo tanto de Veja como de Época, ya se expuso en la Tabla 1.

Época es la más reciente: surge en 1998. Sigue la línea editorial de la revista Focus (Portugal) y de la revista semanal ya citada, Der Spiegel, la más importante de Alemania, Hamburgo, editada por el grupo Spiegel desde 1947. Su proyecto gráfico valoriza el padrón de imagen y de los reportajes. Tal como Veja, confiere relevancia a la educación mediante el proyecto Época en la Educación, que se inició en el 2001. Con las informaciones disponibles en los fascículos distribuidos gratuitamente a las escuelas (cerca de mil unidades), éstas son estimulantes para ejecutar proyectos multidisciplinares para la elaboración de periódicos, revistas, películas e incluso programas radiofónicos a través de Internet. El Proyecto es interactivo por lo que permite el cambio de experiencias entre los maestros involucrados en encuentros presénciales, a lo largo del año, en el eje Rio de Janeiro-São Paulo. 


\section{Análisis del discurso y Norman Fairclough}

A priori, conviene resaltar la distinción entre las denominaciones análisis de discurso y análisis de los discursos. Mientras la primera es más oportuna, existe quien elige la designación análisis de los discursos. Al respecto, el brasileño Milton José Pinto (1999) justifica la adopción de discursos en el plural, mediante la multiplicidad subyacente a la producción de discursos, como también es de utilidad para huir de la categorización abstracta, tal como el estructuralismo donde de inicio el concepto se forma y se solidifica.

Para Maingueneau, el análisis del discurso trabaja sobre textos que son siempre realidades plurissemióticas:

Sea en el texto oral, en que es preciso, en particular, prender por completo la dimensión gestual, o en el escrito, cuya materialidad tiene siempre algo que ver con una imagen. De todas maneras, el analista del discurso no puede jamás tratar la lengua "pura". [...] Realmente existe una gran diferencia entre la semiótica como una disciplina que tiene por objetivo englobar las condiciones de manifestación del sentido en toda su diversidad y las semióticas regionales: semiótica del cuerpo, de la imagen, del cine, de la narrativa, del gesto, etc. Los analistas del discurso recogen de buen grado a las semióticas regionales, pero se muestran desconfiados en lo que concierne semiótica como una disciplina globalizante cuyo estudio del discurso solamente sería una rama (2006).

Para ese mismo autor, hay diferentes flujos teóricos dentro del universo del $\mathrm{AD}$ : etnografía de la comunicación, corrientes pragmáticas, lingüística textual o las problemáticas de Foucault son algunos de ellos y todos tienen su parcela de envolvimiento en el avance de las investigaciones que se agrupan según el rótulo de $\mathrm{AD}$.

En el caso del análisis del discurso pregonado por Fairclough (2001) y adoptado en este estudio, se trata de una línea denominada Análisis Crítico del Discurso que es, además, la misma línea del holandés Teun A. Van Dijk y del alemán Günter Kress y que actúa según la perspectiva de una especie de concienciación acerca del funcionamiento del lenguaje de los discursos sociales. Toma como principales matrices los dictámenes lingüísticos del ruso Mikhail Mikhailovich Bakhtin, la noción de inter-discurso del francés Michel Pêcheux, las categorías de hegemonía y contra-hegemonía del italiano Antonio Gramsci y los conceptos de práctica y de orden discursivo del francés Michel Foucault, además de sufrir una fuerte influencia del marxismo vía Teoría Crítica de la Escuela de Frankfurt.

Para Bakhtin, la lingüística es invariablemente translingüística, una vez que ultrapasa la visión de la lengua como sistema. La lengua no sobrevive de forma aislada y, por lo tanto, el análisis lingüístico, en cualquier circunstancia, incorpora elementos extra-lingüísticos, como ejemplo del contexto como un todo: elemento temporal, histórico y espacial, 
interrelación productor y receptor, además de otros elementos. Más allá, el $\mathrm{AD}$ de Pêcheux visualiza la lengua como un objeto construido por el lingüista y cuyo reconocimiento adviene de su funcionamiento y no de las funciones previamente definidas para las lenguas aunque, como es obvio, lingüista y hablante (usuario de la lengua) actúen de modo distinto en la construcción del lenguaje. Pêcheux cree que el lenguaje se materializa en la ideología y eso se manifiesta en el lenguaje. Concibe el discurso como un efecto de sentidos. Mediante el análisis del funcionamiento discursivo explicita los mecanismos de la determinación histórica de la significación. Para sintetizar, la lengua es ahora analizada según una perspectiva histórica y social.

Fairclough (2001), por su parte, trabaja en consonancia con la noción de hegemonía / contra-hegemonía de Gramsci, para quien, en el modelo capitalista, el poder de las clases dominantes sobre las clases dominadas adviene no solamente del control de los aparatos represivos del Estado, como el gobierno, el ejército, la policía, los tribunales y las prisiones. Es asegurado gracias a la hegemonía cultural, mediante el sistema educacional, las instituciones de carácter religioso y de la fuerza de los media, etc., de forma similar al pensamiento del filósofo francés de origen argelino Louis Althusser, que diseminó la expresión Aparatos Ideológicos de Estado para designar AIE religiosos, escolares, jurídicos, sindicales o mediáticos, entre otros. Fairclough aún hace uso de los conceptos de orden discursivo de Foucault, cuyas críticas están dirigidas al significado de categorías de análisis, vitales para la compresión del funcionamiento del Estado y del ser humano, tales como mecanismos y reglas de poder, soberanía y verdad.

Parece evidente que el $\mathrm{AD}$ requiere, desde el inicio, el entendimiento del discurso como práctica social de producción de textos. En otras palabras, todo discurso consiste no en una construcción individual sino en una construcción social y, por lo tanto, su análisis incorpora siempre el contexto histórico-social en que el individuo está inmerso. Por su parte, el texto es el producto de la actividad discursiva, el objeto empírico del $\mathrm{AD}$, en el que el analista busca las marcas ideológicas presentes aunque el objeto del análisis del discurso sea siempre el discurso en sí mismo. Dicho de otro modo, la interpretación de un texto presupone la existencia de un autor con identidad social e histórica (Fairclough, 2001; Pinto, 1999).

El conocimiento del contexto (situación histórico-social del texto) involucra tanto a la realidad del autor como del lector, incorporando otros textos producidos alrededor de los actores. A partir de ahí, el analista sitúa al discurso como partícipe de esa identidad. Es más: el texto sólo podrá llamarse texto si el lector lo descifra. Resumiendo: el AD requiere el estudio de los sentidos, que incorpora la observancia de la estructura del texto (tal estructura resulta de un movimiento de fuerzas que le es exterior y anterior) y de las formaciones discursivas. Como Magalhães (2003) sintetiza: es preciso delimitar el campo de interpretación a los "sentidos nucleares", comprendidos como la conjunción de 
diversos pequeños significados que se inscriben en torno a una formación discursiva y que, entonces, construyen y consolidan aquel sentido nuclear.

En el caso estudiado, hay que identificar las marcas que definen los discursos de cada uno de los tres títulos aunque sepamos que Veja, Época e IstoÉ no publicitan sus líneas editoriales. Lo cierto es que, empíricamente, el público tiende a asociar $V e j a$ a la oposición al gobierno de Luiz Inácio Lula da Silva y, por consiguiente, lo visualiza como un vehículo comprometido con los partidos políticos conservadores en contraste con la izquierda política. Por otra parte, el gran público asocia, consciente o inconscientemente, los otros dos títulos a una posición neutral.

Para Fairclough (2001), el AD comporta tres prácticas analíticas. La primera de ellas, descripción, prioriza sobre las propiedades formales del texto. La segunda, interpretación, analiza las interrelaciones texto/producción y recepción. La tercera, explicación, delinea la relación entre los procesos de producción y recepción y el contexto social en diferentes niveles: situacional, institucional y social. Hay, entonces, que buscar el sentido del discurso, lo cual está intrínsecamente vinculado a dos mecanismos centrales: la relación entre las partes del texto (en el presente caso, los componentes de la portada y su representación de imagen en su totalidad) y la relación entre el texto y el mundo.

\section{La tragedia del AF 447 y las portadas de Veja, Época e IstoÉ}

Al mismo tiempo en que se disputan espacio en el mercado simbólico, como productos de consumo, las revistas informativas intentan atraer el lector mediante juegos de seducción, que se prestan muy bien al espacio de portada, per se, lugar discursivo de apelo inicial al gran público. Para Magalhães (2003: 100), es en la portada "[...] donde se manifiestan, marcadas por los trazos de la heterogeneidad constitutivas de la cultura, las estrategias enunciativas de cada [...] [título], que se revelan en la superficie discursiva por las técnicas de exhibición de la imagen [...]” y también por el aparato gráfico que cerca la expresión verbal. De hecho, a partir de las portadas de Veja, Época e IstoÉ, en sus ediciones sobre el vuelo Air France 447, se ven semejanzas y diferencias, muy reseñables.

Es preciso rememorar que de acuerdo con Norman Fairclough, en el contenido y en la estructura de los textos, sobre todo los mediáticos, el lenguaje refleja las convenciones y cambios de la sociedad. De ahí, confirmando al semiótico norte-americano C. A. Peirce (1985), se reitera la inexistencia del lenguaje capaz de expresarse en un nivel puramente simbólico o de índice o icónico. Es decir, ningún signo lingüístico es auto-suficiente. La noción de incompleto y de complementariedad lo acompaña siempre. Un ejemplo representativo es la fotografía. Para Barthes (1989: 316), la paradoja estructural fotográfica consiste en el hecho de que la fotografía transmite un objeto inerte en el 
lenguaje pero "[...] transforma la incultura de una arte mecánica en la más social de las instituciones." Al mismo tiempo en que es, por definición, lo real, la fotografía provoca una reducción del objeto a la imagen, reducción ésta que altera la proporción, la perspectiva y el color del objeto. Así, en contraposición al censo común, la fotografía no es la realidad en sí misma y sí su analogon.

La denotación del mensaje fotográfico se origina en el hecho de que, entre todas las estructuras de información, la fotografía es la única constituida por un mensaje que parece agotarse per se. Su plenitud analógica es tan fuerte que aparenta hacer inviable cualquier tentativa de describir; describir en el sentido de acrecentar a la fotografía un código lingüístico, en el que constituye, inevitablemente, una connotación impuesta al análogo fotográfico. Pero el estatuto puramente denotante de la fotografía, vinculado a su perfección y a la aproximación de la realidad pasa a ser un mito, pues existe la opción real de connotación de la fotografía entendida como atribución de sentido traslato o subyacente, a veces, con características subjetivas, que se imprime al mensaje fotográfico y que se da en niveles distintos de la producción fotográfica, como describe por Targino (2004), en análisis sobre el libro de la fotógrafa Susan Sontag, intitulado Delante del dolor delos otros.

Dirimido el primer aspecto - la imposibilidad de completar cualquier signo lingüístico -, mediante el padrón de la fotografía, tan propagada da por su fuerza de imagen, de inicio, se acrecienta que, entre los elementos visuales de las portadas, o sea, los elementos conceptuales que se tornan visibles y gracias a los cuales es posible distinguir o ver, dejando de lado tanto el formato como el tamaño. Eso porque, Veja, Época e IstoÉ mantienen el mismo formato (rectangular) y el mismo tamaño $(21 \mathrm{~cm} \times 25 \mathrm{~cm}$ ). Considerando las etapas adoptadas por Fairclough (2001), antes mencionadas, de descripción, interpretación y explicación, de inicio, llama la atención en el análisis de las portadas de los títulos Veja, Época e IstoÉ la utilización del color.

Aparte de actuar como instrumento de comunicación, es también elemento básico en la identificación y en la visualización de los mensajes, imprimiendo significados particulares a ellas. Un formato se diferencia de su entorno gracias a la utilización del color, en el sentido amplio, incluyendo los matices del espectro, los neutros y todas las variaciones tonales y cromáticas. El color no es más que la luz con una determinada frecuencia: cuanto mayor sea la frecuencia, mayor será la intensidad, o sea, la luz transporta invariablemente un mensaje, que es el color. Consecuentemente, la selección de colores apropiados es fundamental para la lectura de las portadas porque el color actúa sobre la sensibilidad y establece una vinculación directa con las funciones ópticas, fisiológicas y neurológicas. Farina (2002), en Psicodinâmica das cores em comunicação, realiza una exhaustiva descripción acerca de las sensaciones acromáticas y sensaciones cromáticas provocadas por los colores. Ejemplificando: si vinculamos el blanco a la paz 
espiritual, pureza, piedad, dignidad y armonía, y asociamos el negro a la tristeza, el dolor y la negación, ellos asumen interpretaciones distintas, conforme su utilización.

En el caso estudiado, las tres portadas recogen al azul en diferentes tonos más oscuros y más claros. En el espectro visible, se trata de un color de la radiación electromagnética de longitud de onda comprendido, aproximadamente, entre 480 y 510 nanómetros; o sea, forma parte del espectro frío y, por su quietud y confianza, provoca como efectos físicos una sensación relajante y tranquilizante, que se asocia con la parte más intelectual de la mente. Es la remisión del lector a la inmensidad del cielo y al mismo tiempo del mar, insinuando el misterio que cerca el desastre, con el avión perdido en el universo. Cielo y mar se entrelazan. De los cielos, de inicio, la trayectoria majestosa en dirección a la profundidad del océano Atlántico. La prueba más evidente de esta constatación es que hasta en la percepción diccionarista, allí está el apunte azul como sinónimo: "Del color del cielo [...]; del color del mar profundo en día claro; [...]; el cielo, el aire, el firmamento" (Dicionário Aurélio, 2009), con el reconocimiento de que, en la práctica cotidiana, el uso lingüístico consagra esos sentidos.

Por otro lado, mientras Veja e IstoÉ utilizan la representación de la figura de una aeronave, aunque de forma distinta, en Época (Figura 1) la portada es ocupada por el azul en distintas gradaciones que generan sensación de profundidad, yendo de la más oscura a la más clara, reflejando un sombrío en que las tonalidades parecen "resbalar" una hacia el interior de la otra. El predominio de la imagen azul del cielo y del mar parece resaltar los interrogantes acerca del accidente y del destino de la aeronave y de las 228 víctimas. En esa mezcla de azules, "flotan" solamente los datos esenciales de la revista (título; dirección electrónica; número del fascículo; fecha de la edición; logotipo de la editora; precio del ejemplar) más la alusión al impacto de la tragedia (edición especial). Además, tan sólo aparecen cuatro palabras en blanco - Voo Air France 447.

La portada de Época aparece como un todo, texto e imagen conjuntos, que muestran un contraste azul/blanco mientras que los datos sumariamente registrados se mantienen como un eco en la historia humana y de la aviación civil y en la memoria de muchos, para siempre. La economía textual parece decir que las palabras son insuficientes para rellenar la dimensión de la tragedia. Existe un vacío para ser rellenado por cada uno, teniendo en cuenta que, como Fairclough (2001) pregona, la lectura de imágenes refleja siempre la forma de vida de cada individuo porque la historia singular de vida del ser humano no condice con interpretaciones únicas. Asimismo, se nota en el color grisáceo oscuro del cielo, que se asemeja a un día tormentoso, sinónimo de fatalidad. 


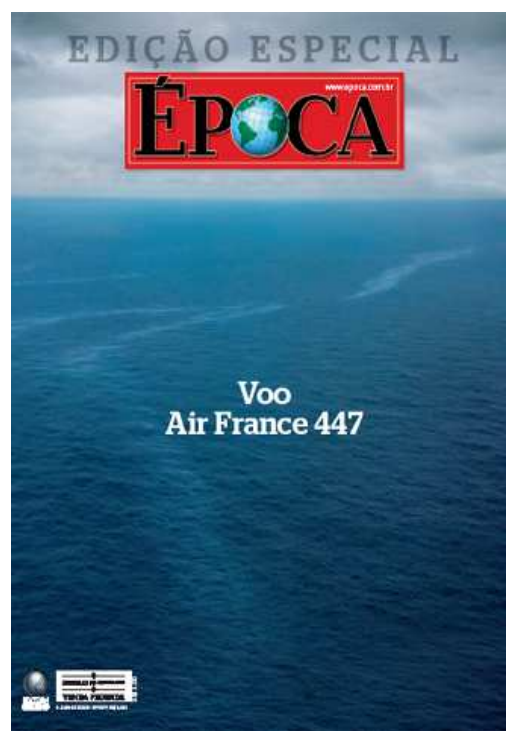

Figura 1 - Portada de la edición de Época, 8 de junio de 2009

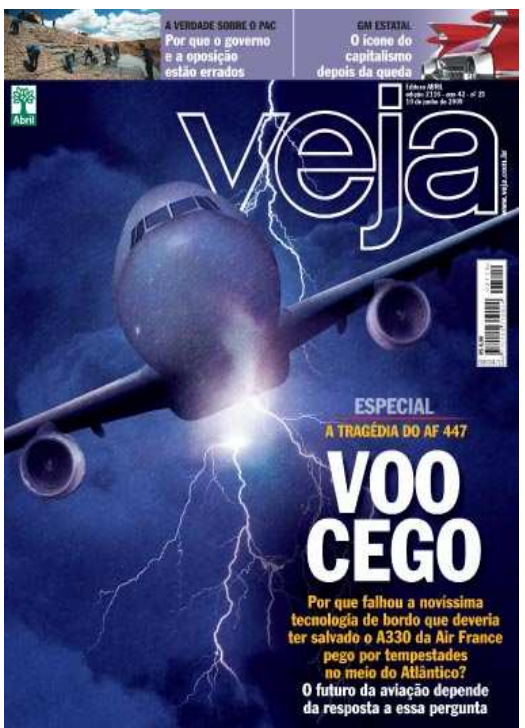

Figura 2 - Portada de la edición de Veja, 10 de junio de 2009

En el caso de Veja e IstoÉ, a pesar de recoger la imagen de un avión, la forma en que es utilizada casi se contrapone. En la primera, el avión casi se sale de la portada en dirección a los individuos-lectores, trayendo consigo la fuerza de los de rayos, que sugieren destrucción y consecuentemente, devastación, destrozo y aniquilamiento. Se asemeja, por ejemplo, a un revólver dirigido hacia el lector, en una imagen plena de agresividad. 
Mientras Época presenta el cielo y el océano como enigma o algo que se esconde, Veja (Figura 2) apunta posibilidades de respuesta: los rayos pueden haber sido la causa del abatimiento del avión. La imagen genera sentimiento de estupefacción ante la tecnología y la naturaleza. Insinúa, así, las causas del accidente y la fragilidad tecnológica para evitarlo, algo que está explícito en el texto que acompaña a los recursos de imagen.

Eso porque, dentro del principio del $\mathrm{AD}$, un código envía al otro información todo el tiempo; además de la imagen, Veja hace un bastante uso del recurso textual. Sin contar los datos fundamentales referentes a la identificación del fascículo (título; dirección electrónica; número de edición, del año y del fascículo; fecha de edición; logotipo de la editora; precio del ejemplar), al contrario de las otras dos cabeceras, cuyas portadas se restringen al accidente aéreo, la portada de Veja, en relación al vuelo Air France 447, expone textos entrecortados, encabezados por la palabra Especial, en los que denuncia la fragilidad tecnológica:

Especial

La tragedia del AF 447

Vuelo ciego

¿Por que falló la novísima tecnología de a bordo (marcación nuestra) que debería tener a salvo el A330 de la Air France abatido por tempestades en el medio del Atlántico?

El futuro de la aviación depende de la respuesta a esa pregunta (2009).

La portada de la revista de mayor circulación en Brasil hace alusión a otras noticias: (1) la verdad sobre el PAC: por qué el gobierno y la oposición están equivocados; (2) GM estatal: el icono del capitalismo después de la crisis.

Siguiendo con la portada de Veja, a pesar del dominio del azul en tonos variados y conducentes al lila, como consecuencia de la inserción de llamadas sobre otras materias, se percibe el empleo de colores vibrantes (rojo y amarillo). El amarillo: un color primario y asociado a la luz y al calor. El rojo, por su parte, es el color de la pasión, del amor y del deseo. Simboliza orgullo, violencia y agresividad, en coherencia, por lo tanto, con la imagen del avión en su fusión con el rayo. En este momento es esencial llamar la atención del hecho de que el color está siendo utilizado en su sentido amplio, incluyendo los matices del espectro, los neutros y las variaciones tonales y cromáticas. Si la composición de colores se presenta de forma diferente para los pigmentos y para las luces, el mecanismo básico del colorido es fruto de la luz (Farina, 2002).

De las tres portadas, la de IstoÉ (Figura 3) es la única que no hace alusión a la tragedia como edición especial. La imagen que ocupa un espacio gráfico significativo, como en Veja, simboliza una aeronave en gran plano. En medio a las tonalidades variadas de azul, sinónimo de tranquilidad y calma, el océano viene entrecortado por el amarillo, color que, como ya se ha dicho, asegura la sensación de calor y plenitud. La imagen de la aeronave 
favorece la visión traslúcida y poética o, según la óptica inversa, la visión oscura y confusa del avión (su sombra).

Sombra como disfraz y simulación. Sombra como aquello que no tiene materialidad y, por consiguiente, asombra. Sombra como espectro. Sombra como el que reproduce por semejanza, motivado por la proyección de luz, un cuerpo sobre una superficie. Sombra como aquello que es doble pero sin la concreción del objeto representado. Sombra como aquello que no explica. Sombra como:

Reproducción, en una superficie más clara, del contorno de una figura que se interpone entre esa y el foco luminoso.

Ausencia de luz [...]

Oscuridad, tinieblas [...]

[...] Mancha.

[...] Fantasma [...]

Vestigio, trazo, señal, indicio.

Cosa impalpable, inmaterial.

[...] Disfrace, apariencia, simulación [...] (Dicionário Aurélio, 2009).

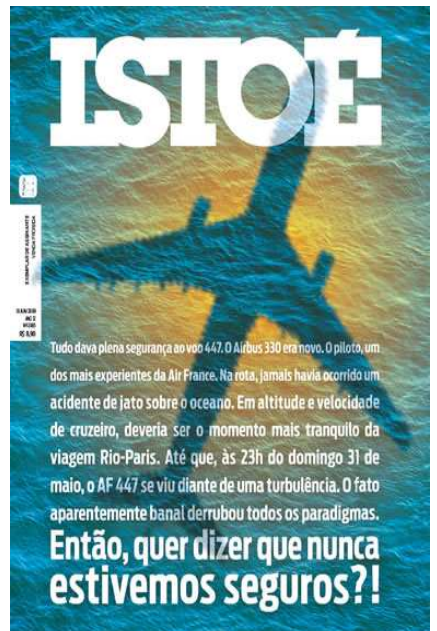

Figura 3 - Portada de la edición de IstoÉ, 10 de junio de 2009

En otras palabras, la imagen prevaleciente en el discurso de la portada de IstoÉ conduce a una interpretación poética o a una interpretación nebulosa, en que el avión reina perdido en el espacio, como mera sombra sobre el océano, quizás, como un ente silencioso en torno de lo que puede haber ocurrido. En compensación, sin contar los datos esenciales inherentes al fascículo (título; número del año y del fascículo; fecha de edición; logotipo de la editora; precio del ejemplar) y de traer el sello de publicidad de la distribución 
gratuita del quinto fascículo del Diccionario Sacconi da Lengua Portuguesa (en rojo y amarillo), abusa de los recursos textuales en blanco en siete líneas con texto justificado más otras dos con un tipo de fuente mucho mayor:

"Todo daba plena seguridad al vuelo 477. El Airbus 330 era nuevo. El piloto, uno de los más experimentados de la Air France. En la ruta, jamás había ocurrido un accidente de avión sobre el océano. En altitud y velocidad de crucero, debería ser el momento más tranquilo del viaje Río-París. Hasta que, a las $23 \mathrm{~h}$ del domingo 31 de mayo, el AF 447 se vio delante de una turbulencia. El hecho aparentemente banal derribó todos los paradigmas. ENTONCES, ¿QUIERE DECIR QUENUNCA ESTUVIMOS SEGUROS?”

Además de la relación entre los elementos más visibles de la portada para buscar el sentido del discurso en la relación texto/mundo, como prevé el experto Norman Fairclough, mediante las concepciones de censo común y las expectativas del gran público, sin duda, las portadas analizadas evidencian los impactos causados por la noticia. Pero es un accidente aéreo con repercusión en todo el mundo, sobre todo, en los 33 países con víctimas, por lo que destaca en el país brasileño y genera una conmoción popularizada, tanto por el elevado número de víctimas brasileñas (58) como por la falta de explicaciones para la tragedia. Ser tema de portada de las tres revistas semanales informativas con mayor circulación (Tabla 1) y la agresividad presente en la portada de Veja (un rayo desestabiliza la aeronave), que se opone a la aparente placidez de Época y hasta de IstoÉ, que sin duda, incitan tal conmoción. La prueba está en el hecho de que los tres reportajes correspondientes trataron exhaustivamente la temática del miedo a volar, como se ejemplifica:

En 2007, después de la tragedia del Airbus de la TAM en São Paulo, el Ibope preguntó a los brasileños si ellos tenían miedo a volar. El resultado: el 74\% dijo que sí. En 1998, ese número era del $42 \%$. La media mundial es del $30 \%$.

La desaparición de un moderno Airbus A330-200 con 228 personas a bordo en medio del Atlántico, en el pasado domingo, reúne todos los componentes que hacen que las personas se pregunten si es seguro volar. Vidas despedazadas en fracciones de segundos, entre ellas niños y recién casados, causan dolor en el corazón. El desastre del vuelo 447 de la Air France, en la ruta Río-París, también evidencia una cuestión específica: illenar un avión de nuevas tecnologías convierte al viaje más arriesgado? (MING, 2009: 83). 


\section{Conclusiones}

Es preciso retomar la relevancia de la revista como medio de comunicación social. Además de la posibilidad de actualización, mantiene las ventajas antes mencionadas crecimiento expresivo en la prensa escrita y electrónica (Tabla 2); camino pari passu con las innovaciones tecnológicas; función educativa cada vez más significativa; interés para públicos distintos y segmentados. Y más que eso, la revista informativa semanal trae los textos debidamente contextualizados. Al contrario de lo que acontece con los periódicos, comprometidos con el acontecimiento del momento, las revistas posibilitan la profundización sobre los hechos registrados, mediante su capacidad de detallar, así como en razón de aspectos específicos de cada título.

Por otro lado, se reitera la idea de que, como el AD concebido por Norman Fairclough prevé, el discurso refleja siempre una visión del mundo vinculada a la de su productor y al segmento social en el que vive. Con base a los autores citados, Bakhtin, Pêcheux, Gramsci y Foucault, Fairclough permite discutir, analizar e interpretar los discursos (en el caso de las portadas), como modalidad singular del lenguaje y de otras manifestaciones simbólicas, reflejando y representando lo constituido y consolidando las relaciones sociales. Luego, la interpretación de las tres portadas de Veja, Época e IstoÉ no obedece a las reglas preestablecidas o a las leyes universales, como ocurre con temáticas ligadas al leguaje visual. Eso porque el mundo percibido es antes todo el resultado de la relación entre las propiedades del objeto y la naturaleza del observador, lo que lleva a afirmar que hay siempre infinitas y múltiples posibilidades. Sólo es preciso desarrollar la sensibilidad para alcanzar un nivel de alfabetización visual, que satisfaga ideales estéticos y del conocimiento. La percepción, en cualquier esfera, está fundamentada en la experiencia y en la carga ideológica de cada uno, lo que invalida cualquier tentativa de generalización.

Además, en el caso estudiado, la mayor dificultad está en definir las marcas discursivas de cada uno de los títulos y consecuentemente, de las nociones que orientan la producción de sus portadas. Además de que Veja, Época e IstoÉ expliciten de forma clara sus líneas editoriales, lo cierto es que las marcas del discurso no están necesariamente vinculadas a las líneas editoriales de los soportes porque son accionadas a partir de las prácticas ideológicas que marcan los discursos; muchas veces, aparte de la consciencia del responsable de la enunciación. Por eso, Magalhães (2003), recogiendo argumentos del argentino Eliseo Verón, defiende que solamente la regularidad y la capacidad de sistematizar en el interior de los discursos caracterizan marcas discursivas. El analista precisa de una cantidad significativa de discursos de un mismo enunciador para apuntar tales marcas. Ejemplificando: ese autor, en el estudio refrendado sobre las portadas de siete ediciones de Veja acerca de la muerte de Paulo César Farias y Suzana Marcolino, para 
identificar las marcas discursivas de esa revista, con más propiedad, recogió a recortes a lo lardo de dos años, espacio donde se ubica la muestra.

De cualquier forma, en el caso de discusión, salvaguardadas esas limitaciones, se infiere que los discursos de las tres portadas se aproximan en algunos momentos, como en el uso del color azul y/o en la introducción de la imagen simbólica de una aeronave y del uso casi excesivo de complementos gráficos, en el caso específico de Veja e IstoÉ. Y es más: a pesar de la visión particular e ideológica de cada enunciador aliado a la carga ideológica de cada individuo, la representación de un accidente de ese porte nos conduce al impacto por ella causado en relación a algunos ítems, como:

1. El futuro de la aviación mundial en términos de seguridad, una vez que Air France es una compañía del Primer Mundo, y, por lo tanto, dotada de potentes recursos tecnológicos.

2. El miedo a volar enfatizado por Ming (2009), de la revista Veja, pero presente en los reportajes de los tres títulos estudiados.

3. El dolor de las familias delante de la ausencia de los entes queridos.

4. El conflicto de responsabilidad provocado entre Brasil y Francia.

5. La impotencia de la tecnología moderna, incapaz tanto de evitar el accidente como de recuperar los destrozos de la aeronave, los cuerpos y la caja negra.

Sin embargo, lo importante es recordar que el $\mathrm{AD}$ mencionado por Norman Fairclough considera al discurso, simultáneamente, texto, interacción y práctica social. Luego, las portadas son producidas para conseguir una respuesta del gran público (interacción entre sociedad y exhibición de la portada), respuesta ésta que deriva y varía de la singularidad individual, de los grupos sociales y de la sociedad como un todo, que en el caso de Brasil reaccionó a la tragedia del AF 447 por cuenta del desarrollo de los medios de comunicación, entre los que destacaron Veja, Época e IstoÉ.

\section{Referencias bibliográficas}

Barthes, R. (1989). O óbvio e o obtuso. Lisboa: Ed. 70.

Dicionário Aurélio. Século XXI. (2009). São Paulo: Ed. Abril.

Fairclough, N. (2001). Discurso e mudança social. Brasilia: UnB.

Farina, M. (2002). Psicodinâmica das cores em comunicação. São Paulo: Edgard Blücher.

Instituto Verificador de Circulação. (2009, noviembre) [“Datos sueltos”]. Obtenido el 1 de nov. de 2009 en http://www.circulacao.org.br.

Magalhães, L. (2003). Veja, IstoÉ, Leia. Produção e disputas de sentido na mídia. Teresina: Edufpi. 
Maingueneau, D. (2006, marzo). "Estudos do texto e discurso". Revista Virtual de Estudos da Linguagem, $\mathrm{N}^{\mathrm{o}} 6$.

Ming, L. (2009, junio). "A tragédia com o mais moderno dos aviões". Veja, ano XLII, pp. 82-84.

Peirce, C. S. (1985). Semiótica e filosofia. São Paulo: Cultrix.

Pinto, M.J. (1999). Comunicação e discurso. Introdução à análise de discursos. São Paulo: Hacker.

Projeto Inter-Meios. (2009, julio). [“Datos sueltos”]. Obtenido el 11 de nov. de 2009 en http://www. projetointermeios.com.br.

Revista Época. (2009, julio). ["Datos sueltos”]. Obtenido el 6 de ago. de 2009 en http://revistaepoca.globo.com.

Revista IstoÉ. (2009, julio). ["Datos sueltos”]. Obtenido el 6 de ago. de 2009 en http://www.terra.com.br/istoe.

Revista Veja. (2009, julio). ["Datos sueltos”]. Obtenido el 6 de ago. de 2009 en http://veja.abril.com.br.

Sant’Anna, J. P. (2009a, mayo). "É hora de garantir o futuro". Meio \& Mensagem, pp. 6-10.

Sant'Anna, J. P. (2009b, mayo). "Nem marola nem tsunami". Meio \& Mensagem, pp. 12-16.

Targino, M. das G. (2004, enero / junio). "Diante da dor dos outros". Revista Brasileira de Comunicação, No 1, pp.163-167.

Targino, M. das G. y Gomes, A. D. (2008, enero / junio). "Informação e jornais de circulação gratuita, Barcelona - Espanha". Revista Brasileira de Ciências da Comunicação, No 1, pp. 51-78. 